\title{
Early Greek Thought and Perspectives for the Interpretation of Quantum Mechanics: Preliminaries to an Ontological Approach.
}

\author{
Karin Verelst and Bob Coecke \\ CLEA-FUND, Free University of Brussels \\ Pleinlaan 2, B-1050, Brussels, Belgium \\ kverelst@vub.ac.be; bocoecke@vub.ac.be
}

\begin{abstract}
It will be shown in this article that an ontological approach for some problems related to the interpretation of Quantum Mechanics (QM) could emerge from a re-evaluation of the main paradox of early Greek thought: the paradox of Being and non-Being, and the solutions presented to it by Plato and Aristotle. More well known are the derivative paradoxes of Zeno: the paradox of motion and the paradox of the One and the Many. They stem from what was perceived by classical philosophy to be the fundamental enigma for thinking about the world: the seemingly contradictory results that followed from the co-incidence of being and non-being in the world of change and motion as we experience it, and the experience of absolute existence here and now. The most clear expression of both stances can be found, again following classical thought, in the thinking of Heraclitus of Ephesus and Parmenides of Elea. The problem put forward by these paradoxes reduces for both Plato and Aristotle to the possibility of the existence of stable objects as a necessary condition for knowledge. Hence the primarily ontological nature of the solutions they proposed: Plato's Theory of Forms and Aristotle's metaphysics and logic. Plato's and Aristotle's systems are argued here to do on the ontological level essentially the same: to introduce stability in the world by introducing the notion of a separable, stable object, for which a 'principle of contradiction' is valid: an object cannot be and not-be at the same place at the same time. So it becomes possible to forbid contradiction on an epistemological level, and thus to guarantee the certainty of knowledge that seemed to be threatened before. After leaving Aristotelian metaphysics, early modern science had to cope with these problems: it did so by introducing "space" as the seat of stability, and "time" as the theater of motion. But the ontological structure present in this solution remained the same. Therefore the fundamental notion 'separable system', related to the notions observation and measurement, themselves related to the modern concepts of space and time, appears to be intrinsically problematic, because it is inextricably connected to classical logic on the ontological level. We see therefore the problems dealt with by quantum logic not as merely formal, and the problem of 'non-locality' as related to it, indicating the need to re-think the notions system, entity, as well as the implications of the operation 'measurement', which is seen here as an application of classical logic (including its ontological consequences) on the material world.
\end{abstract}

\section{Introduction}

At the origin of our approach lay two encounters between Greek thought and Quantum Mechanics, one of them deliberately conceived by its author, the other being a meeting between new QM-concepts and one of the oldest problems of human thinking about the world. The first encounter has been presented in a short lecture by C. Piron ([74, p. 169) in which he attempted to develop a realistic QM-interpretation based on two concepts fundamental to Aristotelian metaphysics, viz. potentiality and actuality. The second one is the doctoral dissertation of D. Aerts 3. It both by content and title dealt with the problem of the One and the Many, the central theme Plato inherited from fifth century philosopher Parmenides of Elea. In what follows we will attempt to make clear that these encounters are not of a purely coincidential nature. We intend to develop in this paper an analysis and re-evaluation of these old questions and their solutions. Our contention is that this analysis might amount into new perspectives on the interpretation of QM, since the enigmas and paradoxes of early Greek thought, and the solutions presented to them in the "classical period" are, more than we realize, bound to mark our way of looking at and reasoning about the world]. The thought-instruments developed by Plato and Aristotle, in order to solve the riddles following out of so called "pre-Socratic" thought, which are epitomized in the, according to both classical thinkers apparent,

\footnotetext{
${ }^{1}$ We find support for the relevance of this position in Schrödinger's fine little book dedicated to the subject ([87], p. 3 sq, p. 159)
} 
contradiction between the "worldviews" of Heraclitus of Ephesus and Parmenides of Elea, are in use up to the present, be it in slightly modified forme2. Our position will be that this classical contradiction has slipped through the ages unimpaired, but in different forms, such as to make it hardly recognisable in our present epistemological and ontological concepts, both in philosophy and in science. A revelation of this implicit presence by reconstructing the outlines of its historical pathway then becomes the necessary first step towards an approach for the tackling of problems it eventually causes in to-day's science. The argument will lead us to the conclusion that the paradoxes appearing in QM represent such a problem. A sketch of some possible strategies will complete this attempt at clarification. Methodologically therefore the arguments in this paper will be based both on scientific and philosophical grounds; even more, it can be considered our aim to show that, when it comes to a proper understanding of the significance and implications of basic "scientific" findings, both are inextricably intertwined, since science, seemingly so different, follows a path of deep conceptions laid down much earlier in the development of human consciousness. We are tempted to see the origins of the QM-paradoxes as consequences of the ontological "choices" of Plato and Aristotle. Their effort concerned the stabilisation of the world of constant change, thus saving the possibility of certain knowledge in order to escape the contradictions between stable and unstable, knowable and unknowable that appear on the level of what happens in reality, as expressed mainly by Heraclitus and Parmenides. This led to the conception of logic as a standardising rule for thinking and, much later, experiment as a standardising rule for experiencing ([34, IV: 99, p. 381). Both originated out of needs felt in the context of the macroworld, and reach now their limitations in the study of the microworld. At the moment when the interactions between things become as important as the things themselves, the separating intervention in reality, first conceptualised by Plato and Aristotle, seems to reveal itself as an illusion. For this reason in this paper no position will be taken in the debate between rationalists and empiricists. From our point of view these philosophical stances come down to the same on the level of the ontological question: all imply the metaphysical world-structure put forward by Plato and Aristotle as a solution for the ontological paradoxes raised by pre-Socratic thought.

\section{The historical context}

Pre-Socratic philosophy (70, Introduction) is the general name given to a rather differentiated group of Greek thinkers, living from the 7 th to the 5th century BC. The two main currents that are of concern to us here are the Heraclitean and the Eleatic school of thought. The Heracliteans claimed to be the followers of Heraclitus of Ephesus, of whose work only some fragments survived. Plato, followed by Aristotle, assigned to him the flux-theory, the doctrine of permanent motion and unstability in the world. The consequences of this doctrine are, as both Plato and Aristotle stressed repeatedly, the impossibility to develop stable, certain knowledge about the world, for an object, changing each instant, does not allow for even to be named with certainty, let alone to be "known", i.e., assigned fixed, objective characteristics. A fragment that might have inspired Plato (45], Cratylus, 66, 402(a); Theaetetus, 72, 160 (d,e)) for this interpretation is the famous riverfragmen 3 in which Heraclitus states that because of the ever ongoing flow of the waters, it is impossible to step into the same river twice. He stresses the ever ongoing change or motion (both being aspects of the same process) that characterises this world and its phenomena. This is so because Being, over a lapse of time, has no stability. Everything that it is at this moment changes at the same time, therefore it is not. This coming together of Being and non-Being at one instant is known as the principle of coincidence of opposites 4 . It is crucial to see that this principle is connected to the possibilty of motion, for being in motion implies to be and to be not at the same time at a certain place on a certain moment. It further implies the unity of the world in the sense that there are no separated object:5, its ontology is dynamic. However, this does not mean that Heraclitus meant to say that there is absolutely no stability in things. The Heraclitean concept of harmony, closely connected to

\footnotetext{
2 "Two great warring traditions regarding consistency originated in the days of the Presocratics at the very dawn of philosophy. The one, going back to Heraclitus, insists that the world is not a consistent system and that, accordingly, coherent knowledge of it cannot be attained by man. (...) The second tradition, going back to Parmenides, holds that the world is a consistent system and that knowledge of it must correspondingly be coherent as well, so that all contradictions must be eschewed." (83], introduction.) A clearer contemporary formulation of the classical position can hardly be imagined!

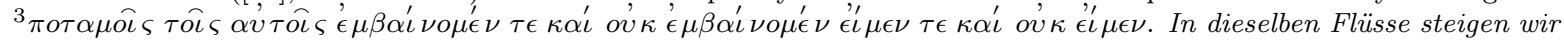
und steigen wir nicht, wir sind und wir sind nicht ([33, DK 49a, p. 161).

${ }^{4}$ The formula stems from Nicolaus Cusanus, a thinker on the edge of the Middle Ages and early Renaissance. But compare e.g. Cusanus's "circular theology" with the meaning of the "Ouroboros", the circular snake of ancient alchemy. For Cusanus, see (34, p. 248 sq.); for the Ouroboros, see (59, p. 367-368).

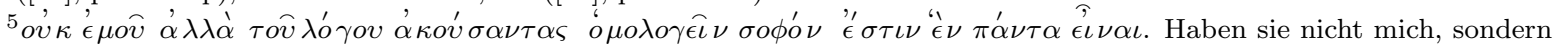
den Sinn vernommen, so ist es weise, dem Sinne gemäß zu sagen, alles sei eins. (33, DK 50, p. 161).

${ }^{6}$ On the (ir)relevance of the flux-theory for Heraclitus's thought and possible interpretations of his concept of $\alpha \rho \mu o \nu^{\prime} \iota \alpha$, see ([56], introduction); also ([57, p. 193).
} 
the principle of coincidence of opposites, rather points in the direction of a permanent and momentaneous re-instantiation of things in the world in a web of totally interconnected events. Reality is One. This does not imply the "unreality" of the things we experience, it states our absolute interconnectedness with the world we experience. Tradition transmitted as its counterpart the Eleatic school, named after its inspirator Parmenides of Elea. Of him more extant textfragments are known, although there remains doubt about their true meaning. This perception of tradition started with Plato and Aristotle, who saw him as the opponent of Heraclitus, learning the non-existence of motion and change in reality, reality being absolutely One, and being absolutely Being7. This brings to mind the paradoxes of Zeno of Elea (57], p. 263 sq.), according to tradition a disciple of Parmenides (45], Parmenides, 204-206, 128(c-d)). The most famous of them is the paradox of motion, a less famous one deals with the possibility of there being separate things in the world: the paradox of the One and the Many. Zeno's until now essentially unresolved paradoxes 8 were intended to show that motion and separated things cannot exist, precisely because their existence demands the coming together of being and non-being at the same time on a certain place at a certain moment in a world whose fundamental feature it is to exist. Non-Being is a contradiction in itself ([93, p. 193). The atomists' reaction to the Eleatic enigma ([57, pp. 407-408) and to our experience of change was the introduction of non-Being in the form of the "void". The void is nothing else than non-Being, in which Being, in the form of a plurality of Eleatic Ones, moves about 9 . They can stick together but not mingle with each other, because of their Eleatic nature10. Change thus reduces to motion, but the origin of this motion, and the paradoxical acceptance of the being of nonBeing, remain riddles unsolved. Because - from the Eleatic point of view - in the real world everything is, eternally and indivisibly, it is impossible to speak of something that is not in a way that makes sense. But, as said before, the "contradiction" seen by classical philosophy between Heraclitus and Parmenides is not necessarily a correct understanding of the earlier "philosophies". One could as well infer that Heraclitus and Parmenides do articulate the same world-experience, the former as the experience of reality over a lapse of time, the latter as the experience of the absolute reality of this moment (to understand better what this means, try to deny by yourself you are experiencing yourself as existing at this moment 11 . This has nothing to do with the intellectual question what it means to exist, or whether our existence is "real" or not. These questions concern things "as such", objects, and their identity in past and future. But this type of interpretation - which is the interpretation of classical philosophy and of science, and which entails a representation of reality outside of its actual and momentaneous experience doesn't make sense, because for Heraclitus no things "as such" do exist, and for Parmenides there is no motion, which implies that there is no time. It is our conviction that, rather than revealing the contradiction between the "thought-systems" of the two pre-Socratic "philosophers", Plato's interpretation reveals the difference between their world-experience and what we think to be ours, constructed on the rational base laid down by classical philosophy. The non-existence of metaphysical worldviews in the pre-Socratic period is then due to a different kind of awareness of one's being-in-the-world that characterized the transition from mythical awareness to rational self-consciousnes ([54, pp. 67. sq.). The hallmark of this awareness is transparance for the stream of events that constitutes the world ([18, pp. 81 sq.); there is no such thing as the separation between subject and object 12 . This separation precisely coincides with the coming-to-be of rational self-consciousness. In philosophy, this change will be codified in the metaphysical systems of Plato and Aristotle. The process found its completion only in the early modern period, when rationalised self-consciousness developed the scientific way of observation and explanation of the world. The problem of change (and motion as a special case of change) and the problem of the existence of separable objects in the world appear as two sides of the same coin. It is at the origin of the principle of contradiction,

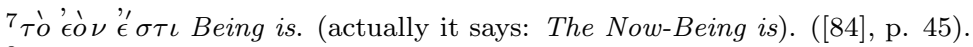

${ }^{8}$ Dijksterhuis remarks sharply: “(...) we don't know how gravity manages to give velocity to the body, and very often the given explanation comes down to pretending to understand on the microlevel what should be explained on the macrolevel. But we know since Zeno of Elea, that here lurks an essential difficulty of the conceptualisation of motion... " (34], p. 203, our translation). See also the comments on modern attempts to explain Newton's laws of gravitation by means of different kinds of bizarre particles, the latest one being the theory of the graviton, by C. Piron in the text of a conference given November 8, 1996 for CLEA in Brussels ([7, , p. 2).

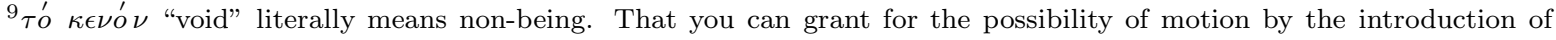
the void was discovered Melissus, a follower of Parmenides, and of whom Leucippus, founder of atomism, was a disciple according to tradition ([57, pp. 397-398). Furthermore ${ }^{\prime \prime} \tau o \mu \circ \varsigma$, i.e., without $\tau o \mu \prime \prime$, without cuts, unseparated in itself, undivided. It is important to see that this originally meant that there are no "parts" in this Being (in this entity, again literally the same word), between which there can be "parts" of non-Being, the non-Being having a different character than the all-pervading, homogeneous, void or empty space of, later times.

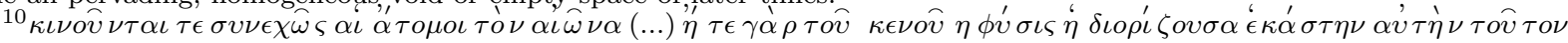
$\pi \alpha \rho \alpha \sigma \kappa \epsilon \hat{v}^{\alpha} \zeta \epsilon \iota$ Les atomes se meuvent continûment durant l'éternité (...) Car la nature du vide, qui sépare chaque atome en lui-même, produit cette effet (...). ([29], in the 'lettre à Hérodote', pp. 102-103)

${ }^{11}$ Mediaeval thought knew this experiencing of experience as the nunc stans, the "standing now". ([10], p. 210)

12 "it is still the primary function of the noos to be in direct touch with ultimate reality." ([6], p. 52)
} 
formulated by both Plato and Aristotle.

The contradicting conclusions deriving from pre-Socratic philosophy were of a major concern to Plato and Aristotle, because they challenged the existence of truth and certainty about the world and therefore about the actions of human beings in it. This uncertainty had given rise to a philosophical discipline, Sophism, that simply denied any relation between reality and what we say about it (45], Theaetetus, $42,152(\mathrm{~d}, \mathrm{e})$ ). Its subjectivism stems from a radical empiricism, which holds that things are for me as I perceive them. But since reality as we perceive it is always in a process of permanent change this implies, as Plato points out in the Theaetetus 13 , also the non-existence of stable, individual things in the world. But then again this means that Sophism is nothing else but an instance of the ontology of permanent change, already formulated by earlier thinkers like Heraclitus. This is what, according to Plato, follows for knowledge out of the ontology of universal change, and "everything is equally true" reveals itself as the epistemological formulation of the coincidence of opposites, which we met before as the base of the universal change theory. On this soil the principle of contradiction rests, because if you allow contradiction, you will be allowed to say whatever: ex falso quodlibet (45, Theaetetus, 150, 182(e)-183(a)). But how to conceal this prohibition with our experience of permanent change in the world? This will only be possible by stabilising human world-experience in a world-picture, strong enough to survive the paradoxical present into the past and the future14. Strong foundations must be laid to grant the possibility to experience entities as objects outside of the stream of events, and therefore to speak about them in an "objective" way. That is where, from our point of view, the true origin of philosophy and in a later stadium science are to be situated. The main problem for Plato and Aristotle can be described therefore as the construction of a world-picture that would 1) grant the ultimate stability of things, neccesary as a solid base for certain knowledge, and at the same time 2) allow for non-being, necessary for the existence of the change, motion, manifold etc., that we experience by our senses. The common feature of both their solutions was the division of the world in two separated, though connected, layers: an unchangeable, motionless 'Parmenidean' or 'Eleatic' one which grants certainty about both objects and names, and a second 'Heraclitean' one, changeable and moving, which allows change and motion in the world as presented to our senses. This feature of a two-layered world (a "world behind the world"), is what makes their worldviews metaphysical (10, One / Thinking, p. 23). In respect to this, we consider the differences between the two as rather superficial. The ways they choosed to achieve this are nevertheless very different. They will be treated in more detail below.

\section{The solutions of Plato and Aristotle}

Plato's system displays an explicit two-world structure: the eternal world of Forms or Ideas, and the world of changeable phenomena. The relation between the two consists in the participation of the phenomena in the Forms, the Forms granting them ultimate stability and knowability. It is the hierarchy in the level of Being (in the level of reality) of the Forms and the participation of things in the Forms (the participation theory) that allows for the possibility of an object to have contrary properties without creating a contradiction between them that would arise out of the simultaneous presence of Being and non-Being 15 The reasoning runs as follows: if there be a Form "Being" and another Form "motion", then it is clear that "Being" must have a deeper, broader level of reality, because everything that moves exists, but not everything that exists moves. Something can be "non-moving" in the sense that it is because it participates in the Form "Being", and is not in the sense that it participates in the Form "Rest" and therefore doesn't move. Because of the different level of reality of the Forms "Being" and "Rest", this will not lead to the ontological impossibility of something not being on the level of Being itself. This constitutes the ontological part of his system. On the level of knowledge this is reflected in the structure of language. Plato is the first to discriminate between the predicative and existential use of the verb "to be 16. This is possible because classes of concepts do "mingle" the same way as classes of Forms ([45], Sophist, 400, 253(b,c); id., 401, 253(d,e)). On the epistemological level, this discrimination plays exactly the same role as the existence-hierarchy of the Forms does ontologically. It allows for the possibility to speak about a thing having contrary properties without ending up in contradiction. Plato thus is the first

\footnotetext{
${ }^{13}$ Plato explicitly refers to Protagoras's "man is the measure of all things, existing and non-existing". (45, Theaetetus, $160(\mathrm{~d}, \mathrm{e}))$

${ }^{14}$ The necessary condition that made possible this construction of stabilising world-pictures or "worldviews", was the earlier coming-to-be of the "inner mind-space", in which the non-present could be re-presented as present ([54], p. 54 sq.).

${ }^{15}$ Plato's elaboration for the Forms Being, Motion and Rest in (45, Sophist, 388, 250(b,c)). A more general ontological formulation can be found e.g. ([45],id., 392, 251(d); 413, 256(d,e)).

16 "Platonists who doubt that they are spectators of Being must settle for the knowledge that they are investigators of the verb "to be". (72], p. 223)
} 
to formulate the principle of contradiction 17. However, since his epistemology remains fully embedded in his ontology, the principle follows as a property of the way we can speak about the world directly out of the participation theory. The principle of contradiction is the formulation on an epistemological level of the participation theory 18 . Plato's epistemology contains, because of this principle, and therefore because of the existence of the Forms, an implicit logical structure 20. The fundamental (and unproven) axiom on which his system rests is the existence of the Forms proper. The stability of things and their knowability is granted by an essence (the Forms) existing before and apart from them. The problem of motion gets its solution by means of the degrees of reality that exist between the Forms mutually. In this way he gives a foundation to the stability of the world and to its knowability, without excluding properties like change and motion out of it. Thus he escapes the pre-Socratic enigma.

Aristotle solves the problem of stability and knowledge - of stability as a necessary condition for knowledge - in an at first glance totally different manner. But he starts from the same premiss: that the world, experienced as external, should be knowable as such, knowable objectively - i.e., in its quality as a collection of objects - by a subject. As said before, this separation of the world and the knower causes the falling apart of the world in the stable, knowable, Eleatic noumenon (essence), and the unstable Heraclitean phenomenon, thus yielding a representation, a metaphysical "worldview" problematic vis-à-vis the changing reality open to experience. The reasons for the Stagiryte's rejection of Plato's system are the difficulties that are raised - from his point of view - by the Form-ontology. The difficulties are threefold: the Third Man, the unlimited number of Forms, and motion ([90], I, 990b(15) - 991a(8); there also footnote c, and 991a(9 sq.)). Aristotle's objections reduce to one major theme: the rejection of the Forms as stabilising essentials existing separatedly from the things they instantiate. How then does he guarantee the existence of stable things that can undergo change and motion without allowing for the coincidence of opposites? And how does he save the possibility to speak about them as being and non-being without falling into contradiction? With him, and contrary to Plato, the Eleatic and Heraclitean layers coincide in one world. A thing (object of experience) is a essential form, a substance which realizes itself in an undifferentiated material receptacl 19, which can be seen as a substratum for existence, not as existence itself. Matter in itself has neither individuality, nor quality. A thing consists of Form and matter at the same time. Things therefore are not reflections of idealised Forms in a separated world, but instantiations of Form - termed substance20 - in matter. This instantiation or realisation is seen as a process in a course of functional development that leads to a certain endpoint, and in this sense as the "goal" to be achieved. How, then, does he explain and justify the nature of things in their coming-to-be and being? This he does by introducing the theory of the four causes. These causes are not to be interpreted in our strict causal sense; they represent the reasons that make that something is what it is (90, I, 983a(24-34)). They are not causes but because21. The material cause is the undifferentiated substratum for existence, in which the essential nature of things will find its expression. The formal cause is exactly this essence, the thing's substantial nature. But because this evolution - this motion towards - takes place in and through the material substrate, it is a process that can never be completed. The efficient cause represents the influences from the outside world that cause the process of motion towards realisation of its true nature. The final cause is the endpoint of this realisation, the completion of the transformation from potentiality to actuality. Why does Aristotle separate potential from realised being? This is the core of his metaphysical system, because the transformation from potential to actual is his way of understanding motion. An entity that has realised its substance doesn't change or move anymore. But this will never be the case for a particular thing in the world, for a thing can only be in motion in reference to something else. And since an endless regression of causes of motion would be absurd, he postulates the existence of the truly actualised and therefore motionless Form, the First and motionless Mover, God. An even more important point is that the impossibility of the total actualisation of the things in the world follows out of their being form and matter at the same time: the entity is not completely its actualised self, it is only in reference to something else. The only truly actualised thing - true Form - is God. Here we find the ontological ground for the contradiction principle: an entity cannot be in the potential and in the actual state in reference to one single other thing (90, IV, 1009a(24-39)). This allows Aristotle to unite the Eleatic and Heraclitean 'worlds' of his metaphysical

\footnotetext{
${ }^{17}$ Already in the Phaedo: (45, Phaedo, 348, 101(d,e)).

${ }^{18}$ Epistemological formulation: [4], Sophist, 414, 257(a,b,c); id. 418, 258(b,c).

${ }^{19}$ The $\dot{v} \pi о \kappa \epsilon \iota \mu^{\prime} \in \nu o \nu$. See (90, VII, 1028b(84)-1029a(34))

${ }^{20}$ It will be noted that "substance" in the Aristotelian sense has nothing to do with the material connotation that seems evident in our use of that concept. Aristotelian reality on the level of matter is a continuum; it is the Form or substance that separates Being from non-Being.

${ }^{21} \alpha \iota$ ' $\tau \iota \rho \varsigma$, cause, bears connotations different from the modern concept of causality. Causal expressions in both the Platonic and Aristotelian sense would include (apart from the 'strictly causal' ones): Why is this statue so heavy? Because it is made of bronze. Why is he taking after-dinner walks? Because of his health. See (92, p. 134).
} 
system. We bring to mind that his system was constructed this way to obtain this result, to grant the possibility to deal with the apparent paradoxical nature of 'real' reality: stability and motion should both be accounted for. The world, thus stabilised ontologically, can now be made accessible to thinking. How does he construct a framework for knowledge such that a relation to this stabilised, but divided reality can be achieved? Here we enter the vast area of Aristotelian logic. The principle of contradiction, based on the separation of being and non-being in the world, can now be established as the basic axiom for correct thinking ([90, IV, 1005b(8-34)). Although Aristotle states explicitly its unprovability (90], IV, $1005 \mathrm{~b}(35)-1006 \mathrm{a}(16))$, its introduction is justified in the framework of his metaphysics, where the danger that it would cause the emergence of a static, Eleatic world-picture, incompatible with our experience, had been neutralised. The three fundamental principles of classical (Aristotelian) logic: the existence of objects of knowledge, the principle of contradiction and the principle of identity, all correspond to a fundamental aspect of his ontology. This is exemplified in the three possible usages of the verb "to be": existential, predicative, and identical. The Aristotelian syllogism always starts with the affirmation of existence: something $i 22$. The principle of contradiction then concerns the way one can speak (predicate) validly about this existing object, i.e. about the true and falsehood of its having properties, not about its being in existence. The principle of identity states that the entity is identical to itself at any moment $(\mathrm{a}=\mathrm{a})$, thus granting the stability necessary to name (identify) it. It will be clear that the principle of contradiction and the principle of identity are closely interconnected. In any way, change and motion are intrinsically not provided for in this framework; therefore the ontology underlying the logical system of knowledge is essentially static, and requires the introduction of a First Mover with a proper ontological status beyond the phenomena for whose change and motion he must account for.

These different positions regarding the stable essence of things will cause the Fight of the Universals, the question whether the substances precede (ante re) or coincide with (in re) the things they instantiate. During the Middle Ages this debate will give rise to a third possible position: nominalism. It holds that substances (Universals) do not exist except for our mental activity. But then the debate had already shifted in a purely epistemological direction, while at its origin were mainly ontological questions. That these questions even in the epistemological treatment of nominalism don't dissappear, becomes clear when one considers the difficulties each nominalist theory has to grant soundly for the possibility to use general concepts, an indispensible tool for scientific theory ([19], p. 85).

\section{Related conceptions in early modernity}

It is well known that the transformation from medieval to modern science coincides with the abolition of Aristotelian metaphysics as the foundation of knowledge. Not abondoned until the twentieth century however was Aristotelian logic as a base for reasoning. Our aim until now can be summarised as showing that the main principle of syllogistic logic, the principle of contradiction, contains itself an ontological rule. The rule is that, contrary to our daily experiences, intellectual processes be standardised to remove change (and as a special case: motion) out of the world to assure the possibility of naming and classifying unambiguously entities as objects. But the change and motion we experience in the world do remain. In the Stagiryte's system, the possibility for change and motion was granted for exclusively on the ontological level (the transformation of potentiality into actuality). Furthermore, although Aristotle separated the disciplines of the theory of Being from the theory of Reasoning (i.e., ontology from epistemology), we showed above that the latter's basic rules and categories are ontological principles as well. Dropping Aristotelian metaphysics, while at the same time continuing to use Aristotelian logic as an empty "reasoning apparatus" implies therefore loosing the possibility to account for change and motion in whatever description of the world that is based on it. The fact that Aristotelian logic transformed during the twentieth century into different formal, axiomatic logical systems used in today's philosophy and science doesn't really matter, because the fundamental principle, and therefore the fundamental ontology, remained the same (40], p. xix). This "emptied" 23 logic actually contains an Eleatic ontology, that allows only for static descriptions of the world. From this point of view, the debate during the Renaissance between the proponents of Aristotelian natural physics and the re-emerging corpuscular theories, can be seen as a debate on how Aristotelian logic as the base of reasoning, given its inherent ontological nature,

\footnotetext{
${ }^{22}$ With Aristotle, negation always is a secondary step in the process of reasoning.

${ }^{23}$ This "emptiness" is different from the "emptiness of twenthieth century formal logic. But the latter can be seen as a natural consequence of the former, since it was developed to deal with logical problems that arise out of the ontological nature of the rules of logic, as we hope to make clear further in this article. This applies e.g. to Russell's "theory of types" (and to all theories based on "meta-reasoning"), that can be read as modern (i. e., "purely epistemological") theories of categories in the Aristotelian sense.
} 
can be brought into agreement with the changing world of our sense:24. This viewpoint also implies that the metaphysical structure fundamental to the older philosophical systems actually remains present in science, be it in a different and, in fact, less clear way.

Our aim is not to describe all subtle differences between the alternative conceptions of the "real world" advanced at the verge of modern science; this has been done by others in a brilliant way; e. g. in 34 and 50. Our concern now is to see whether it is possible to bring at the surface the essential characteristics of a common line of reasoning which would allow to place science back into the philosophical development scetched above, and to check whether this clarification of its its fundamental concepts sheds new light on present-day questions related to the enigma of Quantum Mechanics. Our argument will lead us to the conclusion that this is the case indeed: the ontological role of the Eleatic and Heraclitean layers in the metaphysical reconstruction of reality is played in science by the increasingly absolute conceptions of space and time, instead of but necessarily correlated to the development of modern conceptions of the nature of "matter". This becomes manifest in the "desubstantialisation" of space and in the increasing parallellism between "space" and "time". We will briefly consider the role of "experimentation" as an observational practice designed to apply the ontological rule present in the scientific way of reasoning on our worldexperience, by changing "perception" into "observation". The formalisation of the empirical component of the cognitive, "objectified" world-experience made it possible to bring perception into agreement with the ontological structure of logical reasoning, not the other way around. Therefore the "epistemological" revolution brought about by science can be described not as the abondoning of metaphysics, but as the complete absorption of the metaphysical structure into the procedures of its formalised "operational" components, cognitive and empirical, of this "objective" (i.e., objectified) world-experience. The obscured relation in science between "act" and "perception" then allows for the conception of logical reasoning as a representation of the ontological structure of reality and for the succesfull application of science to the natural world: reality is adapted to the ontological structure of science, not vice vers 25 . The certain base for knowledge is thus granted for in the most absolute sense, the circle is closed: ontology is not a "problem" anymore. In this context the problem of the validity of knowledge takes on a new shape. Epistemology, the critical commentary of the process of science, becomes more and more the philosophical discipline, and can be considered as a discipline or theory of knowledge not separated from, but "without" metaphysics: it nourishes itself ontologically on science. The apparently sole problematic point concerns the relation of the "subject" with the objective world, - the debate between empiricists and idealists, a "question" that for evident reasons never can be "solved" inside its framework: the relation between knowledge and the real world that is implicitly supposed here is replaced in science by the relation between knowledge and a reconstruction of the real world via an "empirical" procedure containing an ontological rule that shapes the relation between the human "observer" and reality on a much deeper level. The separation between subject and object has by now been completed. Let us now see how early modern science solved the problem of "refilling" logic with an ontology that allows for a world of change and motion, and therefore for the description of the world of our sensual experience.

\section{The Solutions of Early Modernity}

At this point in our analysis our problem can be summarised as follows: In the course of a process governed mainly by religious and societal conflicts, early modern natural philosophy emancipated itself from its Aristotelian metaphysical foundation. Although indispensible for its correct understanding, these religious and societal influences do not concern us here; we will confine ourselves to an investigation of how this emancipation was achieved, and by which intellectual means the problems that arose out of it were solved

\footnotetext{
${ }^{24}$ This of course is by no means to say that the debate was considered this way by those who where implied. A brilliant exposure of the backgrounds of the debate between Galilei and the jesuit scientists can be found in [82]. On Newton's backgrounds, see ([35], p. 55 sq.). A more general discussion in [89].

${ }^{25}$ The Greeks, whose intuitions about the relation man-world seem to have been often more clear then ours, were sharply aware of the nature of technical interference with the course of reality. One of the original meanings of the word mhxan, tool, technical device, is 'trick, deceit'. Whether this justifies their distrustful attitude towards it is of course a different matter. This ancient clarity also holds for more fundamental concepts. A quotation from von Fritz is worthwile: "(...) the concepts of the "obscure" Heraclitus are all perfectly clear and can be very exactly defined. In contrast, the empiricist Sextus, whose arguments seem so clear and easy to many readers, has no clearly identifiable concept of either logos ("reason") or nous ("mind") at all. Nous with Sextus is either identified with logos or considered a manifestation of it. Logos, where Sextus speaks in his own name, is most often "logical reasoning" or the capacity of logical reasoning (...). But where Sextus reports the views of other philosophers, logos becomes just the alternative to aisthesis ("perception"), whatever this alternative may be, and so loses all clearly identifiable meaning. Yet it is highly illustrative of the change which the concept of nous had undergone between Heraclitus and Sextus that Sextus, in trying to explain Heraclitus' concept, begins by connecting it with a term the preponderant meaning of which is "reasoning" and ends by almost identifying it with "sensual perception." Heraclitus' own concept of nous, as we have seen, was clearly distinguished from both but somewhat more nearly related to the latter than to the former. (46], pp. 42,43.) Our boldtype and translation of Greek terms.
} 
by its main executors. Therefore we will look into the altenatives that were formulated for the Aristotelian conceptions that came under attack first, viz. of matter and motion, and how the reconciliation with the Eleatic ontology, present unimpaired at the core of Aristotelian logic, was granted for in a way that remains commensurable with the phenomena of change and motion in the natural world. The first step was taken by Galilei in an attempt to explain at first the behaviour of light, later on of all manifestations of matter that are accesible to the senses ([82, chapter I), by re-introducing Democritian atomism as theory of matter and of our perception of it. This implies a quantitative explanation of the qualitative changes that we experience in the macroworld on the level of the basic structure of material bodies; change reduces to motion. Following the same philosophical line, he established the description of the physical behaviour of phenomena observed in standardised conditions by way of mathematical laws, allowing for future verification 26. It was indicated before that atomism requires the introduction of a concept of non-Being or "void", the precursor of "empty space", and the indestructibility and incorruptibility of the "a-tomoi" if it wants to remain logically consistent. Equipped this way it would provide the perfect metaphysical stuffing for logic's hidden ontology, if there would not remain some major deficiencies to deal with, viz. the total lack of understanding of the origin of the motion that it makes logically possible, or the question how the invisible atomoi constitute the sensible things in the world. Nevertheless, in the context of our argument, Galilei's atomism is of uttermost importance. Not only because it was the true reason for his condemnation by the Church [82, but because the re-introduction of corpuscular explanations for the nature and properties of material bodies and the enigma of change and motion was a possible alternative to the Cartesian ontology of the identity of matter and space. This identity followed from Descartes's contention that extension and position are the essential attributes of matter (80], pp. 46-50). For Descartes space is substantial: it is responsable for the fact that something is what it is, exactly because of its position in it. He holds as well that the essential characteristic of material bodies is their extension, and that is why in his system matter and space ultimately coincide. In this way, Descartes remained consistent with the ontological restrictions of the Stagiryte's logical framework. But the impossibility to show that there can be things with these primary qualities alone, makes his system untenable 27. The attempt to develop the possibilities of atomism to a sound philosophical base for the newly emerging science of nature was undertaken by Pierre Gassendi28. His primal concern was a nominalist critique of the concepts of both Aristotle and Descartes, a critique which can be accomplished succesfully only by replacing their logico-ontological categories by "physical" ones. Aristotle's space was to be rejected because it was conceived as an acciden 29 to substantial form, expressed in the famous formula that it is "the number of place". Gassendi was convinced that atomism provided a tool strong enough to overthrow once and for all the Peripatetic doctrine of substances and qualities, while avoiding Cartesian "absurdities" ([16], p. 176) Hence he radically turned upside down the ontological hierarchy grounded by Aristotle but was - as Descartes (80], p. 48) - carefully aware of the necessity to remain within the ontological constraints of its logical formulation 30 . That is why he did not content himself with the reformulation of the "void" of classical atomism, as it leaves the fundamental question of the origin of motion unanswered. The introduction of an atomistic explanation for the nature of material bodies and their properties required a different conception of space as well, for abolishing the categories "substance" and "quality" causes the downfall of the ontology of "potentiality" and "actuality", and therewith of

\footnotetext{
${ }^{26}$ Galilei's famous dual method, composed of Metodo risolutivo (analytical method based on experimental data) and metodo compositivo (synthetical method, generalises the principles found by the former and proves by prediction and verification that they hold for the phenomena under study). ([34, p. 259.)

27 "A good reason for this is the fact that we cannot measure primary qualities at all unless we can perceive secondary qualities. (...) This is the point of Berkeley's argument that a material thing as conceived by Locke is an impossibility", the Lockean "primary qualities" of matter being nothing else than the specification of Descartes' concept of extension. (80, p. 49.)

${ }^{28}$ The importance of whom for the development of key-ideas in early modern science is until today heavily underestimated. It doesn't surprise us much, however, that Schrödinger's finetuned philosophical intuitions recognised this already decades ago. See ([87, p. 75), also ([50], pp. 34, 92-94); (16], p. 174).

${ }^{29}$ In the Peripatetic sense, a quality that cannot exist apart from the substance to which it belongs. We would say a "property", not from a chunk of matter, but from an essential Form.

${ }^{30}$ Gassendi's work presents us with one of the rare instances that reveals, both by content and structure, explicitly the metaphysical nature of the basic categories of modern natural science: "C'est l'idée qui nous parait ressortir de la présentation de la première partie de la Physique dans le Syntagma, le De Rebus Naturae Universe. Cette 'Physique' fait immédiatement suite à la 'Logique' par quoi commence l'ouvrage (...). Il ne s'y trouve pas en effet de 'Métaphysique', et Gassendi s'en explique dès le début: ce n'est pas que la métaphysique soit sans objet, ou inaccesible, c'est qu'il n'y a pas de distinction entre physique et métaphysique (...). Ce sont donc bien des catégories physiques qui prennent ici la place de l'ontologie aristotélicienne, en même temps qu'elles recoivent un contenu opposé à celles de la physique d'Aristote. L'atomisme sera la réalisation adéquate d'un tel projet, mais l'on a vu que celui-ci apparaît (...) à partir de la critique des 'formes substantielles', apporter une nouvelle conception du "mouvement naturel", ressusciter 'l'espace des Anciens' contre le 'lieu Aristotélicien', rétablir le 'vide' dans la Nature, proposer une nouvelle notion du "Temps" etc." ([16], pp. 172-173). Our boldtype.
} 
the possibility to grant for change and motion. Space, infinite, divisible at infinity and indifferent to its material content ([16, p. 179) is the seat of the stable individuality of things. Space constitutes the true Eleactic layer in the metaphysical set-up of natural science: things take position in it while it remains immobile and identical to itself. Space proceeds the material existence of things and is a necessary condition for it, not vice versa; it fulfills the same role as the substances with Aristotle. Atomism, Eleatic by nature, provides a non-qualitative explanation of the composition and motion of material entities in it. Gassendi's real coup, however, is the establishment of the rigorous parallellism between "absolute space" and "absolute time". The conclusions arrived at concerning the ontological status of space will now be applied to time. Time is not the "number of motion" as with Aristotle. It is motion that depends on time, not vice versa. Time constitutes the true Heraclitean layer in the metaphysical set-up of natural science. Gassendi thus reaches the completion of his quest for sound metaphysical foundations for the new natural science: change is motion, while space is the modus of existence of things permanent, exactly the same way as time is the modus of existence of things successive 31 . Here we find another fundamental reason for his rejection of the Cartesian substantiality of space: nobody would defend the substantiality of time. The reality of space and time is extra-substantial and extra-accidential. They have dimensions and/or properties, but, being incorporeal, no functions nor qualities ([16], pp. 177181). Therefore the dimensions of space can coincide with the dimensions of matter without causing any interference. All this clears the road for the theoretical development of the mathematical description of the behaviour of material objects in space and time in terms of their positions and velocities, as had been initiated already by Galilei. The fundamental paradox however, although neutralised again, did not completely disappear. The indivisibility of the atom and the infinite divisibility of space somehow break the strict mutual correspondence between their proper dimensionalities, a necessary condition for their ontological complementarity. The infinite divisibility of space and time 32 implies (following Gassendi) continuity. And continuity, that key-concept to classical mechanics, was the well of which the problems that later led to QM sprang 33 . For Newton, Gassendi's picture provided the perfect ontology to solve the problems inherent in the mechanical description of nature 34. However, Newton realised very well that the force he introduced 35 to explain motion needed itself an explanation ([28, p. 40). Already when writing the Principia he searched for the explanation of the phenomenon the effects of which he adequately described therein. For this explanation he turned, as so often, primarily to the Ancients. Not without disappointment he notes that we do not know of any solution provided by them ([35], p. 57). After various attempts to develop a sound worldview on the base of an "aether" that would allow his "Force" to be transmitted mechanically (35], p. 57-58), he was forced to admit its impossibility, because the effects of such an aether were not observed on planetary motion. Reluctantly 36 but consequently, he introduces "a most subtile Spirit pervading every-body", accounting for both inertial force as the cause of uniform straight-line motion and gravitation as actio in distan 37 . Force thus turns out to be a by necessity immaterial instantiation of space. Not only is force a physical entity with a proper ontological status (32], p. 229), but to bridge the abyss between material and immaterial, between Being and non-Being, this status has to go beyond the categories of existence of the phenomena it should grant for (63, p. 125). It is crucial to realise that Newton needed the co-incidence of God and space to account

\footnotetext{
31 "Il faut en effet, comme il le dira plus loin dans le Syntagma à propos du mouvement, faire une distinction radicale entre le mode d'existence des 'choses permanentes' et celui des 'choses successives', distinction à laquelle correspondent respectivement l'espace et le temps. (...) Espace et temps sont infinis, l'un selon les dimensions, l'autre selon la succesion (...). Espace et temps ont des 'parties inépuisables', d'où la contingence de la situation du monde hic et nunc. Espace et temps sont enfin inaltérables et invariables quel qu'en soit le contenu: ... l'espace reste identique et immobile, comme le temps s'écoule toujours de même manière." ([16], p.179 sq.), our boldtype.

${ }^{32}$ ([69], p. 3). Although we totally agree that "extension" and "divisibility" are at the origin of the present-day QMproblems, we think it established and not without relevance for eventual remedies that these notions are themselves not primitive in this respect, because they follow from past attempts to come to terms with the paradox.

33 "Our helplessness vis-à-vis the continuum, reflected in the present difficulties of quantum theory, is not a late arrival, it stood godmother to the birth of science" (87], p.161).

${ }^{34}$ He uses almost the same wording as Gassendi: "I. Tempus Absolutum, verum, \& mathematicum, in se \& natura sua, sine relatione ad externum quodvis, aequalibiter fluit, alioque nomine dicitur Duratio (...) II. Spatium Absolutum, natura sua sine relatione ad externum quodvis, semper manet similare \& immobile (...)" in ([71, p. 6 (Scholium to the Definitions)). Our boldtype. Reference to this also in ([78, p. 2). "Tempus Relativum" and "Spatium Relativum" are the tools that allow us to measure and describe motion in concreto, thence they are easely confused with 'real' - i. e. absolute - space and time.

35 "What he proposed was an addition to the ontology of Nature." Westfall, R. S., cited in ([28], p. 51). Also ([50], p. 101).

${ }^{36}$ In a letter to Bentley, 25 Feb. 1693, Cited in (28], footnote 42, p. 52.)

${ }^{37}$ In the second edition of the Principia, which dates 1713: "Adjicere jam liceret nonulla de Spiritu quodam subtillissimo corpora crassa pervadente, \& in iisdem latente; cujus vi \& actionibus particulae corporum ad minimas distantias se mutuo attrahunt, \& continguae factae cohaerent; (...) Sed haec paucis exponi non possunt; neque adest sufficiens copia Experimentorum, quibus leges actionum hujus Spiritus accurate determinari \& montrari debent. ([71], p. 173-174). Our boldtype.
} 
for gravity, in exactly the same way Aristotle needed the First Mover to account for motion 38 . PostNewtonian classical physics however, after being purified by eighteenth century enlightement of all such "superfluous" hypotheses, disguised by equating force and accelaration the "causal paradox" that is the consequence of its metaphysical circularity $(32$, p. 228). The persistent problem is the impossibility to prove the existence of an absolute "frame of reference" because the immaterial parameters of space and time escape, at least in principle, experimentally controllable observation. It is exactly this ontological status beyond that makes "similar and immobile" space to the only warrant for the repeatability of experimental observations ([50], p. 84), which is another way to highlight its Eleactic character, and its enigma as well. The essentially Leibnitzian approach of what was called later "analytical mechanics" seemed to deliver an acceptable - because mechanical - alternative, while allowing at the same time for the treatment of similar classes of physical problems as "Newtonian" or "vectorial" mechanics ([58, p. $\mathrm{xxi}$ ). The principle of least action presents a description of mechanical systems by minimizing a quantity that measures the "action" of the system under consideration as if it were a single particle moving in a plenum, the particles of this plenum remaining mutually seperated, but being always in direct contact with each other. The mathematical "configuration space" represents space as if force were the 'real' manifestation of its n-dimensional geometry ([58, p. 13). But this at first glance purely formal approach hides the Cartesian-Leibnizian ontology of the unreality of space, with Descartes because space coincides completely with matter as pure extension; with Leibniz because space is nothing but the relations between the objects 'in' it. That the basic quantity describing with Leibniz the dynamical behaviour of the system, the vis viva or living force 39 , is represented by a scalar is clearly of more than merely formal importance, it is a consequence of his ontological position. This annihilation of non-Being - the vacuum, empty space - from physics opens the possibility to treat space as a merely "relativistic" phenomenon, a position fully supported later by Einstein in the context of his Special Relativity 40 . But the problem of the initial origin of forces or motions remains equally unsolved. Even worse, analytical mechanics lacks a 'natural' way to provide for the stabilising frame of reference for experimental observation as is present in the explicit ontology of the Newtonian treatment. Appearances are saved by stating that the universe presents the same aspect from every point (apart from "local irregularities") ([50, p. 84), but in the ontological setting of the logical framework - i.e., the framework of the separation between Being and non-Being, between system and environment, between cause and effect - this can be uphold only by an act of Divine creation, as is the case with Leibniz, but of course not with his followers in the later school of analytical mechanics. Saying that the notion of absolute space is redundant because the natural laws are invariant under coordinate transformations (48, p. 1) is turning upside down the chain of justifications. As we hope to have made clear by now, the whole metaphysical set-up of natural science is such that they should be so. The fact that the role of "causal black box" played by space is now fulfilled by the "environment" 41 , doesn't change anything to the fundamental circularity of the reasoning.

\section{The Re-emergence of the Paradox: Late Modernity}

The dept of the problem has been brought again to the fore by the results obtained both theoretically and experimentally by QM. For not only does the theory incorporate states for quantum entities that imply non-local behaviour $[8$, but such effects have by now been established incontrovertibly in various experimental settings, thus shortcutting for once and for good eventual attempts to explain them away statistically 42 . Furthermore it was proved to be impossible to describe soundly two or more separated

\footnotetext{
38 "(...) it is possible to see Newton's ideas as the "fruition of a long tradition" extending from Aristotle through Newton, a tradition in which Aristotle's finite plenum was slowly and by painful steps converted into the void, infinite, three-dimensional framework of the physical world required by classical physics. Newton's God-filled space was the penultimate development in the process by which concepts of space were developed by attributing to space properties derived from the Deity; after Newton's time, the properties remained with the space while the Deity disappeared from consideration." ([35, p. 60.) Our boldtype.

${ }^{39}$ Almost identical with our kinetic energy. Together with the "work of the force" or potential energy the two fundamental scalar quantities on which the study of equilibrium and motion of analytical mechanics rests (58], p. xxi).

40 "The introduction of a "luminiferous ether" will prove to be superfluous inasmuch as the view here to be developed will not require an "absolutely stationary space" provided with special properties, nor assign a velocity-vector to a point of the empty space in which electromagnetic processes take place." ([37], p. 38).

41 "What is system, for instance, is described by phases or states; environment is not, and cannot, be represented in such terms. Rather, environment is the seat of "external" forces (...). This apparently necessary and innocent partition of the world into system and environment, (...) has the most profound consequences for the notion of causality. For according to it, the notion of causality becomes bound irrevocably to what happens in system alone, (...) is the state-transition sequence. (...) what happens in environment has thus been put beyond the reach of causality. Environment has become acausal." ([85], p. 19). Our Boldtype.

${ }^{42}$ C. Piron in [76]: “... the orthodox QM (the 'new testament' as Pauli named it) with its credo and its principles is dead and definitively dead." A lot of acrobatic attempts where made to rescue the modernist picture, by extending the quantum
} 
systems within the present formalism [3]. As is sufficiently known, the state of a physical system in QM is described within mathematical Hilbert space. For every physical entity the collection of all its properties constitutes its state in Hilbert space. Exactly in the same way as the state of a classical entity is represented in phase space, the Hilbert space contains all possible states the system can possibly have. In this sense, both phase space and the Hilbert space represent the environment in which the dynamical transition of one state to another of the entity will take place. To avoid that the individual state be blurred in the statistical ensemble proper to the 'orthodox' interpretation, C. Piron introduces a new notion of physical state based on the concept of property as related to experimental projects with welldefined certain results ([75, p. 398). These results are called yes-results, while any other outcome is considered to be a no-result. To this end, a test that could eventually be performed is associated to a property of the system under consideration, in such a way that, once you are certain in advance to obtain the desired result, you can assign to the system an element of reality ([74], p. 170) as conceived by Einstein ([38, p. 137). Introducing Aristotle's dynamical terminology, a property is called "actual" when the result of the test is certain; when uncertain it is said to be "potential" ([74, p. 171). A property conceived this way is always potential or actual. It is however possible that the property tested by an experimental project, and the one tested by the experimental project obtained by exchanging the "yes" and the "no" results of the former, are both potential. Whenever this situation appears we are dealing with quantum-like entities, contrary to classical ones where this can never be the case. But it is not $a$ priori obvious how to define a particular entity and thus how to assign properties to it. All comes down to account for the set of tests which matches the collection of its properties and thus the entity itself. This presupposes the possibility to separate the phenomenon under consideration from the rest of the universe 31. But, although it is stated explicitly that the certainty of the experimental project is an objective feature of the system without reference to our knowledge or beliefs ([69], p. 5), we are supposed to know in advance what to do with the system to get this certain result. Indeed, the system should be prepared in a precise way that is related to our existing knowledge of its properties. This presents no problem when we are dealing with phenomena that are accessible to our daily experience, like with the breaking of a piece of chalk ([76], p. 208.). The necessary assumptions about its properties are then given by our daily experience. This enables us to drop the preparation procedure that is essential to 'true' experimental observation. Experimental observation is indeed more than the "contemplation of the astronomer" ([69], p. 8), it is an intervention that prepares the system in such a way that we obtain an entity - separated from its environment - together with a set of properties determined by the possible yes-no experiments. Again, it is the preparation of the system that moulds the 'real thing' so as to fit in a definite metaphysical set-up, primarily by separating "the system" out of its "environment". Whatever be the structure of the set of possible answers, the modelisation of the set of possible yes-no experiments imposes on the set of possible properties the mathematical structure of a complete lattice ([53], p. 844). This means, as indicated before, that the "real thing" is forced to fit into the scheme of an intrinsically Eleatic ontology. The preparation procedure is a 'black box' generating that ontology. This does not imply that it is senseless to perform experimental projects. Natural laws are verified by experimental observation, and experiments are performed in reality, so there must be some kind of agreement with what happens in reality. But it is precisely the kind of relationship that exists between reality and experimental observation that should be rendered more clear; which implies that the consequences of the fact that each experimental project is an intervention in reality should be itself subject of investigation. By making explicit the structures underlying the sets of possible yes-no questions and of possible answers, the Geneva School approach realises an important progress in this respect, though until now the ontological aspect of the problem has been left untouched. Embarking on an analysis of this aspect could nevertheless shed some light not only on the relation between the "entity" and the "real-world phenomenon", but also on the status of our conceptions of space and time, which form, as has been argued, the ontological foundation for the metaphysical set-up present in scientific theory. This provides the background against which Piron's attempts to get hold of a "realistic" conception of space are to be seen. The inevitable re-appearance of ontological circularity to which also these attempts are subject can be clarified on a more theoretical

picture with an underlying modernist kind of world (for example D. Bohm [17), or by rejecting it (for example A. Einstein [36] and J. Bell [13]). But at the same time, every advance on an experimental level (in particular A. Aspect [11] and H. Rauch 81]) confirmed that these attempts were bound to fail. The general community of physicists reacted to this by a kind of ontological ignorance attitude which evolved towards a pragmatic quasi botanic empiricism, or by some new age like mystification tendencies (see for example 'The Tao of Physics' by F. Capra). Alternatively, a not unimportant group of people saw the inadequate arsenal of mathematical (and in particular logical) tools as the origin of all these problems (especially J. Von Neumann \& G. Birkhoff [15], J Jauch [52, C. Piron [73, H. Neumann \& G. Ludwig 60, 61] and D. Foulis \& C. Randall [42]). This gave rise to an enormous development of mathematical attributes and structures, of which quantum logic is the most known among philosophers of science (see for example 14 and in particular 65]). Unfortunately, the mathematical expertise required made the development and study of quantum logic an essentially mathematical occupation such that the conceptual development stagnated (a confirmation of this fact can be found in [66] and [77]). 
leve 43 . The tacit assumption underlying the position that a thing coincides with a collection of properties is that "being" in the sense of "existence" is but a property amongst the others. We discussed before at length why this assumption is untenable in the context of an - implicit or explicit - Eleatic ontology as the one present in the cognitive and empirical procedures of science. The notions "object" or "entity" necessitate the introduction of Being in some form, ontologically beyond the object's predicable properties, so as to grant for its required stability and separability, as well as for an origin for the dynamics governing the processes of change and motion to which it is exposed. In this ontological setting to be is not a property. It follows that existence is not a predicate $([80$, p. 36) and existence itself is not within reach of experimental preparation, nor observation ([50], p. 84). Regarding the paradoxical results attained by QM, we are led then to the conclusion that only the development of an explicit and properly ontological foundation for basic categories as 'entity', 'motion' as well as for the intervention represented by their experimental observation remains open as a fruitful strategy. A sketch of a possible further elaboration of the results attained thus far by the Geneva School with regard to the foregoing analysis is presented in the last section of this paper. Alternatively, leaving behind the principle of contradiction as constituting ontology at the core of scientific procedure both empirical and cognitive, could be taken into consideration. Interesting steps to come to terms with problems related to this approach have been made in the recent past. From attempts to develop logical systems that escape the rigorous consistency demanded by the principle of contradiction sprang relevant considerations, but these remain trapped within the framework of the ontological core common to all logical system 44 . Another approach recognises the ontological nature of the problem, but limits itself to the construction of ontologies for "possible worlds" that fit "a" logic in which the principle of contradiction has been "neutralised" somehow [83]. Since all logics still do partake in the same fundamental principle, these "possible worlds" necessarily remain Eleatic. Our position would be that the origin of the problem resides within the ontological nature of reality itself. This viewpoint might clarify the incurable presence of paradoxes in logical systems of all kinds. Paradoxes then would appear because of an ontological incompatibility between logic and "real" reality. Therefore our approach would be to take paradox itself as the starting point for the construction of an ontological framework. We see the work of Spencer Brown 88 , and, more recently, Kaufman 45 as supportive in this respect. That this strategy might open relevant perspectives for QM is indicated by the recent discovery of Aerts et al [7. The principle underlying such ontology has been adequately formulated in the past. It is the already mentioned principle of coincidence of opposites, to be found in the work of fifteenth century philosopher Nicolaus Cusanus. It provides an excellent example to show that abandoning the principle of contradiction implies the loss of neither the capacity to reason soundly, nor the possibility to use mathematics ([30, viz. Capitula XII to XVII). It does imply, however, the necessity to abandon on a conscious level the artificial separation between "subject" and "object", the distance between things being a mere aspect of their instantiation. As an indication for its operational viability we suspect the possibility to consider circularity and self-reflexivity as tools rather than as problems. Another interesting possibility might be the development of a sound conception of "physical space", homogeneous from all points, because circumference and center coincide in all points, and without the need to introduce a force-like "First Mover", since distance and interaction reveal themselves as the same thing. This again might add to opening up interesting perspectives on the "non-locality" of elementary physical phenomena manifest at the core of QM.

\footnotetext{
${ }^{43}$ A specific discussion of this problem with respect to Piron's approach of space and time will be the subject of a future publication. Equally problematic but outside our scope would be an analysis of the concept of 'field', arising out of General Relativity. Be it sufficient to refer to Schrdinger, who explains: "at any rate the very foundation of the theory, viz. the basic principle of equivalence of acceleration and a gravitational field, clearly means that there is no room for any kind of 'force' to produce accelaration save gravitation, which however is not to be regarded as a force but resides on the geometry of space-time." ([86, p. 1). This 'making real' of the geometry of space as the 'force' behind dynamical processes in four-dimensional space-time reveals more clearly the underlying ontology and links General Relativity firmly to the 'Leibnizian' tradition within physics. But this continuum, in which gravity manifests itself, is itself the source of a host of ontological problems. Regarding this, Piron cites in his lecture Einstein saying "that according to general relativity space is endowed with physical qualities and in this sense an ether exists (...) but this ether must not be thought of as endowed with the properties of ponderable media (...) nor may any concept of motion be applied to it." ([79, p. 1, 2). Our boldtype. By trying to explain his own concept, Einstein reveals how close Newton and Leibniz actually stand.

44 "Every logician in the end divides propositions into those which are acceptable and those which are not." ([40], introduction)

${ }^{45}$ Oral communication; see also 55 .
} 


\section{Contemporary physics as products of early Greek thought: Post-Modernity and beyond?}

Let us now concentrate on one of the words in the title which might seem rather innocent and obvious, namely 'products'. In a first reading of this title one could think that it might easily be replaced by 'result' or 'onsequence'. We nevertheless attach a very definite meaning to this word 'product' which is definitely not covered by 'result' nor 'consequence'. In contemporary mathematics, which deals with the study of families of well-defined formal structures (or, in a more advanced language, 'categories of mathematical objects 46 ), products of two structures that belong to the same family (i.e., two mathematical objects that belong to the same category) are usually defined as a third structure in this same family which has the two given structures as 'faithful' substructures (in categorical language this means that there exist structure preserving maps, called 'morphisms', from the two given objects into the product object). In fact, this means that the product is larger than the given structures, but essentially not different. This way of defining products is an obvious consequence of the specific 'scientific method' in the context of which mathematics is used: one only wants to deal with objects that are well defined. Once one has defined such a well-defined collection of objects, one sticks with it and studies it. Even more, an object has only a meaning as an element of this well-defined collection. As a consequence, if one wants to introduce operations on the objects in this collection in order to study and characterize it, one remains faithful to this collection, i.e., one does not leave it47. This situation in mathematics had a major influence on the way how people tend to describe compound systems in physics: for a given description (i.e., structural characterization) of individual physical entities one is still attached to the idea that the compound system should be described within the same family of structural characterizations. Within the context of Newtonian mechanics, this does not pose a problem. Within the context of QM however, one is able to produce a description procedure for the joint system, but looses completely the mathematical consistency 48 required for a 'good theory'. Unfortunately, by yielding the conclusion that the 'Hilbert space structure', the structure in which QM-entities are described, is not 'the good universal structure' for their description, these results have only fostered the search for 'bigger' and 'bigger' structures in which one could hope to find 'consistent products' for the description of the compound system. Never the a priori idea of universality has been put into question. According to our previous sections, we think that this specific attachment to universality of a description points the finger at the real problem at the source of this malaise concerning the description of compound entities in physics. The presence of a second entity in a compound system definitely changes the context of the first one, and as such, a description that incorporates a contextual ingredient should take this presence into account in an explicit way ${ }^{49}$. Unfortunately, for the QM formalism, this is not the case 50 . Solving this problem comes down to starting from correct collections of primitive notions in order to reconstruct the proper formalization for the concept under consideration, in this case the concept of compoundnes:51. With the goal to aim to an as reduced as possible reformulation of the formalism that arises when one starts from as few as possible primitive notions, Moore started a categorization program 52 for the foundations of physics (see [67, 68, 69]). Within this scheme, other primitive notions have been incorporated (see [9, 23, 24, 25, 27]), yielding a categorical description of the concept of compoundness (see [27]). Without falling into the trap of empirical fragmentation 53 , it seems to be possible for this concept to skip the universality principle which has always been the a priori for theoretical physics. One could wonder whether other physical concepts could be treated in the same way? A conclusive question? When dealing with 'questions'

\footnotetext{
${ }^{46}$ For an outline of the mathematical theory of categories introduced by Eilenberg and Mac Lane [39] we refer to [12,62 64]. In fact, some approaches and authors on category theory see a possibility of introducing 'aspects of undefinedness' within this formalism, and consider this aspect as the main argument to apply category theory as a foundation for mathematics.

${ }^{47}$ We have to remark that quite recently, since the development of the mathematical theory of categories, one became very interested in 'relating' the different well-defined collections of mathematical objects. However, one is still attached to the same kind of scientific method, but now on a meta-level.

${ }^{48}$ This inconsistency is encountered as well on a purely structural level, in the sense that there exist two unequivallent procedures for obtaining a so called tensor product (see [2]), both when one starts from an operational or empiricist point of view (see [3, 77] and [91]).

${ }^{49}$ For the reasons stated before, this could considerably enhance the coherence of the theory.

${ }^{50} \mathrm{An}$ explicit construction in which one of the present authors tries to take the context into account for a situation of 'the many' (see 22 27]), based on ideas developed by Aerts, Gisin and Piron in 4, 5] and [47, and yielding the framework of [5] and [21, shows that in the traditional Q.M. description, aspects like the order in which one performs consecutive measurements on different individual pseudo-entities within the compound system are even not a part of the context, but an ingredient of the formal representation of the entity itself.

${ }^{51} \mathrm{~A}$ more detailed discussion on this matter can be found in 69.

${ }^{52}$ This program, when consistently developed in the total framework of the theory, could amount in an explicit Aristotelian ontological set-up, exactly in the sense Piron 74 intended.

${ }^{53}$ Which occurs as wel on a theoretical as on a operational level.
} 
we are confronted again with the problem of definedness. Old and endless debates on the yes or no necessity of explicit representations of 'states' of reality could definitely be omitted by allowing aspects of undefinedness within the explicitation of a concept such as states and experimental projects; quoting Moore on the later in 69 p.3: "I shall take a particular physical system to be some part of the ostensively external phenomenal world, supposed separated from its surroundings in the sense that its interactions with the environment can either be ignored or effectively modeled in a simple way. The restriction to a reasonably circumscribed aspect of a phenomenon is crucial: physics is, first and foremost, the study of detailed models of specific situations ... I shall take a definite experimental project relative to a physical system to be a real experimental procedure where we have defined in advance what would be the positive response should we perform the experiment ... Of course the specification of a precisely delimited positive response is also an idealization: in general terms, all that we require from an assignment rule is that it be sufficiently clear in each case whether or not one should assign the response 'yes', this within subjectively reasonable limits with respect to borderline cases"; where he motivates the necessity of consecutive and complementary 'idealizations' by: "... the problem of linguistic demarcation in the face of vagueness or contextuality." As it is very reasonable to consider human creation as an ability to 'invent' new objects outside an a priori given class $\{x \mid \phi(x)\}$ with a characterizing predicate form $\phi$, the collection of possible designable experimental projects cannot be a class and in particular, cannot be a set. To quote Moore (private communication, 27-09-97): "... this boils down to a kind of object-subject dichotomy: states and properties are about the exterior world and definite experimental projects are about the internal world. Building physical theories is a fallible attempt to relate one to the other ..." Still, any operational theory attempts to remain unaware, by formal ignorance, of these possible creative acts consisting of designing definite experimental projects. This ignorance could be motivated by the ever ruling set theoretical basis for mathematics. In order to understand the problems that arise, one could consider entities like my past or the entity's past, also studied in [25]. It is obviously impossible to define a predicate $\phi$ that characterizes all my possible pasts that I can have on a next instance of time, since this would require Laplace's supreme intelligence: having all knowledge on possible events that might be imposed by the context between now and the considered next instance of time. Contrary to the existence of a set of states as a criterion for the reality of an entity, the existence of properties as reference to the elements of reality in the Geneva approach [3, 67, 69] can be the starting point for a more flexible setup: the entity 'my past' for example can be described by consecutive creations of properties, themselves not being part of a predefined set. This idea has been generalized and taken as a starting point of of a formal scheme refered to as the Induction 54 formalism, which takes in an a priori (and not only in an explanatory) way 'creation' into account, as well 'human' creation (choice/invention) as 'material' creation (mutual Induction as interaction), and of which a complete technical development can be found in 9 , 25, 26, 27. This approach succeeds in avoiding the aspects of isolation in the definition of an entity: the 'particular physical system' fuzzyness to which Moore referes is explicitely not present. As such, this strategy aims at the elaboration of the results of the Geneva school in the direction of a formalism that is explicitly compatible with the results of the foregoing ontological analysis. Formally as well as conceptually, such a theory of creation, by constituting the description of the emerging properties of the entities as possible parts of compound systems, treats "interaction with the context of an entity as a part of a measurement process (cfr. 4, 5, 21, 23.)" and "entanglement of individual entities (cfr. [22, 27])" on the same level, i.e., in terms of mutual Induction of properties (cfr. 9, 25, 27]). We finally want to remark that the idea of going beyond definedness, going beyond set-large collections of states, seems to be most conveniently expressed through the use of so-called quasi-categories (cfr. 1] p.31), a generalization of the above mentioned mathematical categories, of which the undeniable necessity thus emerges from both physical and metaphysical considerations. To quote Hersh in [49] p.22-23: "... We can try to describe mathematics, not as our inherited prejudices imagine it to be, but as our actual experience tells us it is. ... What are the main properties of mathematical knowledge, as known to all of us from daily experience? (1) Mathematical objects are invented or created by humans. (2) They are created, not arbitrarily, but arise from activity with already existing mathematical objects, and from needs of science and daily life ..."

\section{Acknowledgments.}

We thank Sonja Smets, Hubert Dethier, Wilfried Van Rengen and Rudolf De Smet for discussing the content of this paper. We thank David Moore for the indication of problems and references connected to the subject of this paper. We thank D. Durlinger for technical help while implementing the ancient Greek font. Bob Coecke is Post-Doctoral Researcher at Flanders' Fund for Scientific Research.

\footnotetext{
${ }^{54}$ Here, 'induction' does not refer to any of its usual philosophical significances, but rather refers to physical theories like electro-magnetism.
} 


\section{References}

[1] J. Adámek, H. Herrlich and G.E. Strecker, Abstract and Concrete Categories, J. Wiley \& Sons (1990).

[2] D. Aerts and I. Daubechies, Helv. Phys. Acta 51, 661 (1978).

[3] D. Aerts, The One and the Many, PhD-thesis, Free University of Brussels (1981); Found. Phys. 12, 1131 (1982).

[4] D. Aerts, J. Math. Phys. 27, 202 (1986).

[5] D. Aerts, Found. Phys. 24, 1227 (1994).

[6] D. Aerts, B. Coecke and S. Smets, 'On the Origin of Probabilities in Quantum Mechanics: Creative and Contextual Aspects', in G. Cornelis and J.P. Van Bendeghem, eds., Einstein Meets Magritte: Metadebates, Kluwer Academic Publishers (1998).

[7] D. Aerts, J. Broeckaert, S. Smets, 'A Quantum Mechanical Description of the Liar Paradox', submitted for the proceedings of the 20th Int. conf. on Philosophy, Boston (1998).

[8] D. Aerts, 'The Entity in Modern Physics: the Creation-Discovery-View of Reality', in E. Peruzzi, ed., Identity and Individuality of Physical Objects, Springer Verlag, Berlin (1998).

[9] H. Amira, B. Coecke and I. Stubbe, 'How Quantales Emerge by Introducing Indiction in Operational Theories', Preprint, FUND-DWIS, Free University of Brussels (1998).

[10] H. Arendt, The life of the mind. One / Thinking, one-volume edition, Harcourt Brace Jovanovich Publishers, London (1978).

[11] A. Aspect et. al., Phys. Rev. Lett. 49, 1804 (1982).

[12] M. Barr and C. Wells, Toposes, Triples and Theories, Springer (1995).

[13] J. Bell, Physics 1, 195 (1965).

[14] E.G. Beltrametti and B.C. van Fraassen, eds., Current Issues in Quantum Logic, Plenum (1981).

[15] G. Birkhoff and J. von Neumann, Ann. Math. 37, 823 (1936).

[16] O.R. Bloch, La philosophie de Gassendi. Nominalisme, Matérialisme et Métaphysique, Martinus Nijhoff, La Haye (1971).

[17] D. Bohm, Phys. Rev. 85, 166 (1952).

[18] J. Campbell, The Masks of God, volume I, Primitive Mythology, Arkana, Penguin Books, N.Y. (1991).

[19] R. Carnap, Empiricism, Semantics, and Ontology, in R. Boyd, P. Gasper and J.D. Trout, eds., The Philosophy of Science, MIT press, Massachusetts (1992).

[20] H.N. Castaneda, Plato's theory of relations, in M. Bunge, ed., Exact Philosophy, D. Reidel Publishing Company, Dordrecht (1973).

[21] B. Coecke, Hidden Measurement Systems, Doctoral Dissertation, Free University of Brussels (1995); Helv. Phys. Acta 70, 442 (1997); Helv. Phys. Acta 70, 462 (1997).

[22] B. Coecke, 'A Representation for Compound Quantum Systems as Individual Entities: Hard Acts of Creation and Hidden Correlations' and 'A Representation for Spin-S Quantum Entities as 2S Individual Spin-1/2 Quantum Entities', Found. Phys., to appear (1998).

[23] B. Coecke and F. Valckenborgh, Int. J. Theor. Phys. 37, 311 (1998).

[24] B. Coecke and D.J. Moore, 'Decompositions of Probability Measures on Complete Ortholattices in Join Preserving Maps', Preprint, FUND-DWIS, Free University of Brussels (1998).

[25] B. Coecke and I. Stubbe, 'On a Creation-Based Extension of Operational Theories', submitted for the proceedings of the 20th Int. conf. on Philosophy, Boston (1998).

[26] B. Coecke and I. Stubbe, 'Quantum Mechanics as a Theory of Induction', Preprint, FUND-DWIS, Free University of Brussels (1998). 
[27] B. Coecke, 'Compoundness as Diagrams in Quasi-Categories', notes of a lecture given at IQSAAtlanta, August 1997; B. Coecke and I. Stubbe, 'The Category of Mutual Inductions for Entities Described by Pseudo States', In preparation (1998).

[28] B.I. Cohen, 'Newton's third law and universal gravity', in P.B. Scheurer and G. Debrock, eds., Newton's scientific and philosophical legacy, Kluwer academic publishers, Dordrecht (1988).

[29] M. Conché, 'Epicure. Lettres et maximes', texte établi par Marcel Conché, PUF, Paris (1987).

[30] De Cusa, N., De Docta Ignorantia, in E. Hoffmann and R. Klibansky, eds., Lipsiae, In Aedibus Felicis Meiner (1932).

[31] W. Daniel, Bohr, Einstein and Realism, Dialectica 43 (1989).

[32] E. Dellian, 'Inertia, the innate force of matter', in P.B. Scheurer and G. Debrock, eds., Newton's scientific and philosophical legacy, Kluwer academic publishers, Dordrecht (1988).

[33] H. Diels and W. Kranz, Fragmente der Vorsokratiker, erster Band, Weidmann, Dublin, Zürich, 1971.

[34] E.J. Dijksterhuis, De mechanisering van het wereldbeeld, 7th ed., Meulenhof, Amsterdam (1950-1996).

[35] B.J.T. Dobbs, 'Newton's alchemy and his 'active principle' of gravitation', in P.B. Scheurer and G. Debrock, eds., Newton's scientific and philosophical legacy, Kluwer academic publishers, Dordrecht (1988).

[36] A. Einstein, E. Podolski and N. Rosen, Phys. Rev. 47, 777 (1935).

[37] A. Einstein, 'On the electrodynamics of moving bodies', in The principle of relativity. A collection of original papers on the special and general theory of relativity. Notes by A. Sommerfeld., Dover publicatons, New York (1952).

[38] A. Einstein, 'Can quantum-mechanical description of physical reality be considered complete?', in J.A. Wheeler and H.Z. Wojciech, eds., Quantum Theory and Measurement, Princeton University Press, Princeton (1983).

[39] S. Eilenberg and S. Mac Lane, Trans. Am. Math. Soc. 58, 231 (1945).

[40] R.L. Epstein, The semantic foundations of Logic, Vol. I, Kluwer academic publishers, Dordrecht (1990).

[41] B. d'Espagnat, Conceptual Foundations of Quantum Mechanics, W.A. Benjamin (1976).

[42] D.J. Foulis and C.H. Randall, 'Manuals, Morphisms and Quantum Mechanics', in H. Marlow, ed., Mathematical Foundations of Quantum Theory, Accademic Press. (1978).

[43] D.J. Foulis, C. Piron and C.H. Randall, Found. Phys. 13, 813 (1983).

[44] D.J. Foulis and C.H. Randall, Found. phys. 13, 843 (1983).

[45] H.N. Fowler, Plato in twelve volumes, Loeb Classical Library, Heinemann, London (1967).

[46] K. Von Fritz, 'Nous, noein, and their derivatives in pre-Socratic philosophy', in A.P.D. Mourelatos, ed., The Pre-Socratics, a colletion of critical essays, Princeton University Press, Princeton (19741993).

[47] N. Gisin and C. Piron, Lett. Math. Phys. 5, 379 (1981).

[48] R. Harré, 'The redundancy of Spacetime: Relativity from Cusa to Einstein', in D. Aerts, ed., Einstein Meets Magritte: White Book, Kluwer Academic Publishers (1998).

[49] R. Hersh, in T. Tymoczko, ed., New Directions in the Philosophy of Mathematics p.9, Birkhäuser (1986).

[50] M. Jammer, Concepts of Space. The history of theories of space in physics, 3th ed., Dover Publications, N.Y. (1954-1993).

[51] J.M. Jauch and C. Piron, Helv. Phys. Acta 36, 827 (1963). 
[52] J.M. Jauch, Foundations of Quantum Mechanics, Addison-Wesley (1968).

[53] J.M. Jauch and C. Piron, 'On the structure of quantal proposition systems', Helv. Phys. Acta bf 42 (1969).

[54] J. Jaynes, The origin of consciousness in the breakdown of the bicameral mind, Houghton Mifflin Company, Boston (1976).

[55] L. Kaufman, 'Virtual Logic', in D. Aerts, ed., Einstein Meets Magritte, Kluwer Academic Publishers (1998).

[56] G.S. Kirk, Heraclitus. The Cosmic Fragments, Cambridge University Press, Cambridge (1975).

[57] G.S. Kirk, J.E. Raven and M. Schofield, The Presocratic Philosophers. A critical history with a selection of texts, Cambridge University Press, Cambridge (1983).

[58] C. Lanczos, The variational principles of mechanics, fourth ed., Dover publications, New York (1970).

[59] G. Luck, Arcana Mundi. Magic and the Occult in the Greek and Roman Worlds. A collection of Ancient Texts, The Johns Hopkins University Press, Baltimore and London (1985).

[60] G. Ludwig, 'An Axiomatic Basis of Quantum Mechanics', in H. Neumann, ed., Interpretations and Foundations of Quantum theory, B.I.-Wissenschaftsverlag (1981).

[61] G. Ludwig and H. Neumann, 'Connections between Different Approaches to the Foundations of Quantum Mechanics', in H. Neumann, ed., Interpretations and Foundations of Quantum theory, B.I.-Wissenschaftsverlag (1981).

[62] S. Mac Lane, Categories for the working Mathematician, Springer (1971).

[63] J.E. McGuire and P.M. Rattansi, 'Newton and the 'Pipes of Pan", Notes and records of the Royal Society of London 21 (1966).

[64] C. McLarty, Elementary Categories, Elementary Toposes, Oxford Sci. Publ. (1995).

[65] P. Mittelstaedt, 'Classification of Different Areas of Work Afferent to Quantum Logic', in E.G. Beltrametti and B.C. van Fraassen, eds., Current Issues in Quantum Logic, Plenum (1981).

[66] D. Moore, Helv. Phys. Acta 66, 471 (1993).

[67] D. Moore, Helv. Phys. Acta 68, 658 (1995).

[68] D. Moore, 'Closure Categories', Int. J. Theor. Phys., to appear (1997).

[69] D. Moore, 'On State Spaces and Property Lattices', British J. Phil. Sc., to appear (1998).

[70] A.P.D. Mourelatos, The Pre-Socratics, a collection of critical essays, Princeton University Press, Princeton (1974-1993).

[71] Newton, I., Isaaci Newtoni, Opera quae extant omnia, Commentariis illustrabat Samuel Horsley, Londini: exc. Joannes Nichols (1889).

[72] G.E.L. Owen, 'Plato on Non-Being', in G. Vlastos, ed., Plato: a collection of Critical Essays, vol I, Doubleday (1971).

[73] C. Piron, Foundations of Quantum Physics, W.A. Benjamin (1976).

[74] C. Piron, 'Le réalisme en physique quantique: une approche selon Aristote', in The concept of physical reality. Proceedings of a conference organized by the Interdisciplinary Research Group, University of Athens (1983).

[75] C. Piron, Erkenntnis 16, 398 (1981).

[76] C. Piron, 'Quantum Mechanics Fifty Years After', in P. Lahti and P. Mittelstaedt, eds., Symposium on the Foundations of Modern physics, World scientific (1985).

[77] C. Piron, Mécanique Quantique Bases et Applications, Presses Polytechniques et Universitaires Romandes, Lausanes (1990). 
[78] C. Piron, 'Un nouveau regard sur le monde physique', preprint, Université de Genève (1996).

[79] C. Piron, 'Quantum Mechanics and Relativity: two failed revolutions', in D. Aerts, ed., Einstein Meets Magritte: White Book, Kluwer Academic Publishers (1998).

[80] A. Quinton, The Nature of Things, Routledge \& Kegan Paul, London and Boston (1973).

[81] H. Rauch, Helv. Phys. Acta 61, 589 (1988).

[82] P. Redondi, Galilei, eretico, Einaudi, Turino (1983).

[83] N. Rescher and R. Brandom, The logic of inconsistency. A study in Non-Standard Possible-World Semantics and Ontology, Basil Blackwell, Oxford (1980).

[84] K. Riezler, Parmenides, Text, Übersetzung, Einführung und Interpretation, Vittorio Klostermann, Frankfurt a. M. (1970).

[85] R. Rosen, 'The Roles of Necessity in Biology', in Newton to Aristotle. Toward a Theory of Models for Living Systems, Birkhäuser, Boston, Basel and Berlin (1989).

[86] E. Schrödinger, Space-Time Structure, Cambridge University Press, Cambridge (1950-1985).

[87] E. Schrödinger, Nature and the Greeks and Science and Humanism, Canto, Cambridge University Press (1954-1996).

[88] G. Spencer Brown, Laws of Form, George Allen and Unwin, ltd., London (1969).

[89] S. Toulmin, Cosmopolis, the hidden agenda of modernity, University of Chicago Press, Chicago (1984).

[90] H. Tredennick, Aristotle. Metaphysics, books I-IX, Loeb XVII, Loeb Classical Library, Harvard University Press, Cambridge, Massachusetts (1996).

[91] B.C. van Fraassen, Quantum Mechanics, Clarendon Press, Oxford (1991).

[92] G. Vlastos, 'Reasons and causes in th Phaedo', in G. Vlastos, ed., Plato: a collection of Critical Essays, vol I, Doubleday (1971).

[93] G. Vlastos, Studies in Greek Philosophy, volume I: The Presocratics, Princeton University Press, Princeton (1993).

[94] J. von Neumann, The Mathematical Foundations of Quantum Mechanics, Princeton University Press (1955). 